\title{
Avaliação crítica da legislação brasileira de sucos de fruta, com ênfase no suco de fruta pronto para beber
}

\section{Critical assessment of the Brazilian regulations}

on fruit juices, with emphasis on

ready-to-drink fruit juice

\author{
Alessandra Carvalho FERRAREZI ${ }^{1}$ \\ Karina Olbrich dos SANTOS² \\ Magali MONTEIRO'
}

RE S U M O

O objetivo deste trabalho foi realizar a avaliação crítica da legislação brasileira de sucos de fruta, com ênfase no suco de fruta pronto para beber. De acordo com a legislação brasileira, os sucos industrializados devem atender à legislação específica, estando de acordo com a definição e a designação que os identificam e com os parâmetros de qualidade estabelecidos, devendo também atender à legislação sobre rotulagem de alimentos embalados. Foi observado que existem lacunas na legislação brasileira de sucos que favorecem sua interpretação equivocada, além da inclusão de sucos não regulamentados no mercado. Mudanças freqüentes, e diferentes informações, nas legislações de rotulagem concomitantemente vigentes, além do uso indevido de expressões no rótulo, também podem levar à interpretação equivocada. Para que se possa conhecer e usar adequadamente a legislação é necessário torná-la clara e mantê-la constantemente atualizada. Adicionalmente, sua ampla divulgação também deverá contribuir para uma escolha consciente na hora da compra.

Termos de indexação: Informação. Legislação sobre alimentos. Rotulagem de alimentos. Suco de fruta.

\section{A B S T R A C T}

The aim of this work was to critically assess the Brazilian regulations on fruit juices, with emphasis on ready-to-drink fruit juice. According to the Brazilian regulations, bottled fruit juices must follow specific regulations. They should be in accordance with the definition and designation that identify them, with the

\footnotetext{
1 Universidade Estadual Paulista Júlio de Mesquista, Faculdade de Ciências Farmacêuticas, Departamento de Alimentos e Nutrição. Rod. Araraquara-Jaú, km 01, Caixa Postal 502, 14801-092, Araraquara, SP, Brasil. Correspondência para/Correspondence to: M. MONTEIRO. E-mail: <monteiro@fcfar.unesp.br>.

2 Embrapa Caprinos. Sobral, CE, Brasil.
} 
668 | A.C. FERRAREZl et al.

quality parameters established, and especially, follow the Brazilian food labeling regulations. The Brazilian regulations on bottled fruit juices have some gaps that promote their misunderstanding and marketing of substandard juices. Frequent changes, divergent labeling regulations and inappropriate use of expressions on the label can also lead to misinterpretation. Food regulations need to be clear and updated frequently if they are to be known and followed. Additionally, their wide dissemination should contribute to informed choices when buying.

Indexing terms: Nutrition facts. Legislation foods. Food labeling. Juices.

\section{N T R O D U Ç Ã O}

O mercado brasileiro de suco de fruta industrializado vem crescendo rapidamente nos últimos anos ${ }^{1}$. O suco de fruta pronto para beber é o principal responsável por essa expansão, que vem acompanhando a tendência mundial de consumo de bebidas que oferecem saúde, conveniência, sabor, inovação e prazer-4. . O suco de laranja pronto para beber é um dos sucos mais vendidos no Brasil ${ }^{4}$. Os sucos devem atender à legislação específica, estando de acordo com definição, classificação, registro, padronização e requisitos de qualidade, devendo também atender à legislação sobre rotulagem de alimentos embalados $^{5-6}$

A legislação brasileira na área de alimentos é regida pelo Ministério da Saúde, por intermédio da Agência Nacional de Vigilância Sanitária (ANVISA) e pelo Ministério da Agricultura, Pecuária e Abastecimento (MAPA).

As bebidas são regulamentadas pela Lei $n^{\circ}$ 8.918, de 14 de julho de 1994, do MAPA, e regida pelo Decreto $n^{\circ} 2.314$, de 4 de setembro de 1997, que dispõe sobre a padronização, a classificação, o registro, a inspeção, a produção e a fiscalização de bebidas ${ }^{5,6}$. Posteriormente, o Decreto $n^{\circ} 3.510$, de 16 de junho de 2000, alterou dispositivos do Decreto $n^{\circ} 2.314$, de 19977. A rotulagem dos sucos de fruta prontos para beber deve atender às exigências da ANVISA sobre rotulagem de alimentos embalados, conforme os Regulamentos Técnicos da RDC n 259, de 20 de setembro de 2002, sobre rotulagem de alimentos embalados, a RDC $n^{\circ} 360$, de 23 de dezembro de 2003, sobre rotulagem nutricional de alimentos, a Portaria $n^{\circ} 27$, de 13 de janeiro de 1998, referente à informação nutricional complementar, a RDC n 359, de 23 de dezembro de 2003, sobre porções de alimentos embalados para fins de rotulagem nutricional, e a Lei $\mathrm{n}^{\circ}$ 10.674, de 16 de maio de 2003, que obriga todos os produtos alimentícios comercializados a informar sobre a presença de glúten ${ }^{8-12}$.

O objetivo desse trabalho foi realizar um levantamento e uma avaliação crítica da legislação brasileira de sucos, com ênfase no suco de fruta pronto para beber, a fim de compreender suas exigências com relação ao suco de laranja e à rotulagem.

\section{Legislação brasileira de suco de fruta}

O Decreto $n^{\circ} 2.314$ do MAPA, de 1997, estabelece os Padrões de Identidade e Qualidade de bebidas, os registros, a classificação, a padronização e a rotulagem, bem como as formas de controle das matérias-primas, das bebidas e dos estabelecimentos. Neste Decreto encontra-se a definição de bebida, como sendo "todo produto industrializado, destinado à ingestão humana, em estado líquido, sem finalidade medicamentosa ou terapêutica". As bebidas são classificadas como bebidas não-alcoólicas ou alcoólicas. Os tipos e as definições das bebidas não-alcoólicas são contempladas nos artigos 40 a 60 da Seção I, incluindo suco ou sumo (Art. 40), Polpa de fruta (Art. 41) e Néctar (Art. 43). Suco ou sumo é definido como: "a bebida não fermentada, não concentrada e não diluída, destinada ao consumo, obtida da fruta sã e madura, ou parte do vegetal de origem, por processo tecnológico adequado, submetida a tratamento que assegure a sua apresentação e conservação até o consumo" ". $\mathrm{Na}$ mesma Seção I também estão incluídas as defi- 
nições de suco desidratado, suco misto, suco reconstituído, a designação do termo integral e a denominação concentrado para o suco parcialmente desidratado. O Decreto $n^{\circ} 3.510$, de 2000, acrescenta ao Art. 40 a definição de suco tropical ${ }^{6,7}$.

O Decreto $n^{\circ} 3.510$, que modifica o inciso III, do Art. 40, do Decreto $n^{\circ} 2.314$, estabelece que ao suco poderá ser adicionado açúcar na quantidade máxima fixada para cada tipo, através de ato administrativo, obedecendo ao percentual máximo de $10 \%$, calculado em g açúcar $/ 100 \mathrm{~g}$ de suco ${ }^{7}$. Ainda, de acordo com a Lei $n^{\circ} 8.918$, de 1994, em seu Art. $5^{\circ}$, parágrafo 4 e o Decreto $n^{\circ}$ 2.314, em seu Art. 22, Seção IV - Da rotulagem de bebidas, que consta do Capitulo II, do Título I, no caso de açúcar ser adicionado ao suco, deve-se anunciar no rótulo que se trata de um suco adoçado. A adição de aromas e corantes artificiais em sucos é proibida e não é permitida a associação de açúcares e edulcorantes hipocalóricos e não-energéticos, respectivamente de acordo com o Art. 40 do Decreto $n^{\circ} 2.314^{5,6}$.

O suco desidratado "é o suco sob o estado sólido, obtido pela desidratação do suco integral, devendo conter a expressão suco desidratado", conforme o Art. 40 do Decreto ${ }^{\circ} 2.314$, que também denomina suco concentrado o suco que for parcialmente desidratado, devendo, de acordo com o acima citado Art. 22, ser mencionado no rótulo o percentual de sua concentração6.

O suco reconstituído, a designação integral e o suco misto também são definidos no Art. 40 do Decreto $n^{\circ} 2.314$. O suco reconstituído é definido como: "o suco obtido pela diluição de suco concentrado ou desidratado, até a concentração original do suco integral ou ao teor de sólidos solúveis mínimo estabelecido nos respectivos padrões de identidade e qualidade para cada tipo de suco integral, sendo obrigatório constar de sua rotulagem a origem do suco utilizado para sua elaboração, se concentrado ou desidratado, sendo opcional o uso da expressão reconstituído"6.

A designação integral refere-se ao suco na concentração original da fruta, isto é, ao suco proveniente somente da fruta, sem adição de açúcar, sendo vedado o uso da designação integral para suco reconstituído6.

O suco misto é definido como: "o suco obtido pela mistura de duas ou mais frutas e das partes comestíveis de dois ou mais vegetais, ou dos seus respectivos sucos, sendo a denominação constituída da palavra suco, seguida da relação de frutas e vegetais utilizados, em ordem decrescente de quantidades presentes na mistura" ${ }^{6}$.

Os sucos e bebidas à base de frutas são ainda regulamentados por Instruções Normativas que obedecem à Lei $n^{\circ}$ 8.918, de 1994 e ao Decreto $n^{\circ} 2.314$. A Instrução Normativa $n^{\circ} 1$, de 7 de janeiro de 2000, aprova o Regulamento Técnico geral para fixação dos Padrões de Identidade de Qualidade (PIQ) para polpa de fruta, constando em seus anexos o PIQ para sucos de fruta. A Instrução Normativa $n^{\circ} 12$, de 4 de setembro de 2003, aprova o Regulamento Técnico para fixação do PIQ geral para suco tropical e néctar ${ }^{13,14}$.

De acordo com o Art. 43 do Decreto $n^{\circ}$ 2.314, néctar "é a bebida não fermentada, obtida da diluição em água potável da parte comestível do vegetal e açúcares ou de extratos vegetais e açúcares, podendo ser adicionada de ácidos, e destinada ao consumo direto". Não é permitida a associação de açúcares e edulcorantes hipoenergéticos e não-energéticos na fabricação de néctar ${ }^{6}$.

O Art. $3^{\circ}$, da Instrução Normativa $n^{\circ} 12$, define que: "o néctar cuja quantidade mínima de polpa de uma determinada fruta não tenha sido fixada em Regulamento Técnico específico deve conter no mínimo $30 \%(\mathrm{~m} / \mathrm{m})$ da respectiva polpa, ressalvado o caso de fruta com acidez ou conteúdo de polpa muito elevado ou sabor muito forte e, neste caso, o conteúdo de polpa não deve ser inferior a $20 \%(\mathrm{~m} / \mathrm{m})^{\prime \prime 14}$.

A definição de suco tropical está incluída no Decreto $n^{\circ}$ 3.510, de 2000, (parágrafo 6, inciso $V$ do Art. 40, Decreto $n^{\circ} 2.314$ ), como "o produto obtido pela dissolução, em água potável, da polpa de fruta polposa de origem tropical, não 
fermentado, de cor, aroma e sabor característicos da fruta, através de processo tecnológico adequado, submetido a tratamento que assegure a sua apresentação e conservação até o momento do consumo"7.

O Decreto $n^{\circ} 3.510$ (parágrafos $7^{\circ}$ e $8^{\circ}$, do inciso V, Art. 40, Decreto $n^{\circ} 2.314$ ), estabelece que "os teores de polpa e as frutas utilizadas na elaboração do suco tropical serão fixados em ato administrativo do MAPA, devendo ser superiores aos estabelecidos para o néctar da respectiva fruta" e enfatiza que "poderá ser declarado no rótulo a expressão suco pronto para beber ou expressões semelhantes, quando ao suco tropical for adicionado açúcar", respectivamente ${ }^{7}$.

De acordo com o Art. 41 do Decreto $n^{\circ}$ 2.314, polpa de fruta é definida como "o produto não fermentado, não concentrado, obtido de frutas, por processos tecnológicos adequados com teor de sólidos em suspensão mínimo, a ser estabelecido em ato administrativo do MAPA" 6 . A Instrução Normativa $n^{\circ} 1$, de 2000 , contempla o PIQ para polpa das seguintes frutas: acerola, cacau, cupuaçu, graviola, açaí, maracujá, caju, manga, goiaba, pitanga, uva, mamão, cajá, melão, mangaba, e para suco das seguintes frutas: maracujá, caju, caju alto teor de polpa, caju clarificado ou cajuína, abacaxi, uva, pêra, maçã, limão, lima ácida e laranja. Vale destacar que o Regulamento Técnico para fixação do PIQ para suco de laranja contempla a definição, composição, ingredientes opcionais e declara que o suco de laranja deve obedecer a esse PIQ fixado para suco de laranja. Assim, de acordo com essa Instrução Normativa, suco de laranja é definido como a "bebida não fermentada e não diluída, obtida da parte comestível da laranja (Citrus sinensis), através de processo tecnológico adequado". Quanto à composição, o suco de laranja deve obedecer às características de cor amarela, sabor e aroma próprios e apresentar "limite mínimo para teores de sólidos solúveis totais de 10,5 ${ }^{\circ}$ Brix (a $20^{\circ} \mathrm{C}$ ), para relação de sólidos solúveis em brix/acidez de 7,0g/100g de ácido cítrico anidro e para teor de ácido ascórbico de $25 \mathrm{mg} / 100 \mathrm{~g} "$, além de "limite máximo para teores de açúcares totais naturais da laranja de $13 \mathrm{~g} / 100 \mathrm{~g}$ e para óleo essencial de laranja de 0,035\% (v/v)"13.

A Instrução Normativa n 12, de 2003, em seu Art. $1^{\circ}$, aprova "o Regulamento Técnico para Fixação dos Padrões de Identidade e Qualidade Gerais para Suco Tropical; os Padrões de Identidade e Qualidade dos sucos Tropicais de Abacaxi, Acerola, Cajá, Caju, Goiaba, Graviola, Mamão, Manga, Mangaba, Maracujá e Pitanga; e os Padrões de Identidade e Qualidade dos Néctares de Abacaxi, Acerola, Cajá, Caju, Goiaba, Graviola, Mamão, Manga, Maracujá, Pêssego e Pitanga, constantes dos Anexos I, II e III, respectivamente, desta Instrução Normativa" ${ }^{14}$.

O Art. $2^{\circ}$, da Instrução Normativa $n^{\circ} 12$, considera "como frutas polposas de origem tropical, na elaboração do suco tropical, as seguintes frutas: abacate, abacaxi, acerola, ata, abricó, açaí, abiu, banana, bacuri, cacau, caju, cajá, carambola, cupuaçu, goiaba, graviola, jenipapo, jabuticaba, jaca, jambo, mamão, mangaba, manga, maracujá, melão, murici, pinha, pitanga, pupunha, sapoti, seriguela, tamarindo, taperebá, tucumã e umbu"14.

De acordo com o item 2 do Anexo I da acima citada Instrução Normativa $n^{\circ} 12$, "é vedada a designação suco tropical ao suco que não necessite de água na sua elaboração e que não seja proveniente de fruta de origem tropical". No item 3, consta que: "o suco tropical cuja quantidade mínima de polpa de uma determinada fruta não tenha sido fixada em Regulamento Técnico específico, deve conter um mínimo de 50\% $(\mathrm{m} / \mathrm{m})$ da respectiva polpa, ressalvado o caso de fruta com acidez alta ou conteúdo de polpa muito elevado ou sabor muito forte que, neste caso, o conteúdo de polpa não deve ser inferior a 35\% $(\mathrm{m} / \mathrm{m})^{\prime \prime 14}$.

Ainda, no item 3, do mesmo Anexo I, consta que "o suco tropical pode ser obtido a partir de suco concentrado de fruta de origem tropical", conforme o subitem 3.2.5. O item 8, traz no subitem "8.2. É proibida a designação de Suco Integral"; no subitem "8.3. É obrigatória a declaração, 
de forma visível e legível, do percentual mínimo, em peso, da polpa da respectiva fruta utilizada na elaboração do Suco Tropical..."; no subitem "8.5. No Suco Tropical pronto para beber deve ser declarada a palavra adoçado"; e no subitem "8.6. O Suco Tropical, quando obtido de suco concentrado, deve declarar, na lista de ingredientes, esta origem"14.

A rotulagem dos sucos e bebidas à base de fruta também deve atender às exigências da ANVISA sobre rotulagem de alimentos embalados conforme a RDC $n^{\circ} 259$, de 2002, a RDC n 360, de 2003, a RDC n 359, de 2003, a Portaria $n^{\circ}$ 27, de 1998, e a Lei $n^{\circ} 10.674$, de $2003^{8-12}$.

Na RDC n²59, em seu Anexo único, item 1 , consta que "o presente Regulamento Técnico se aplica à rotulagem de todo alimento que seja comercializado, qualquer que seja sua origem, embalado na ausência do cliente, e pronto para oferta ao consumidor". No subitem 2.1., a rotulagem é definida como "toda inscrição, legenda, imagem ou toda matéria descritiva ou gráfica, escrita, impressa, estampada, gravada, gravada em relevo ou litografada ou colada sobre a embalagem do alimento". De acordo com o subitem 3.1., os alimentos embalados não devem apresentar rótulo que utilize "vocábulos, sinais, símbolos, emblemas, ilustrações ou outras representações gráficas que possam tornar a informação falsa, incorreta, insuficiente, ou que possa induzir o consumidor a equivoco, erro, confusão ou engano, em relação à verdadeira natureza, composição, procedência, tipo, qualidade, quantidade, validade, rendimento ou forma de uso do alimento" 8 .

Ainda, no subitem 3.1., da RDC n²59, o rótulo não deve atribuir aos alimentos embalados efeitos ou propriedades que não possuam, bem como, indicar que o alimento possui propriedades medicinais ou terapêuticas ${ }^{8}$. O item 4 , relata que "a informação obrigatória deve ser escrita no idioma oficial do país de consumo..." e o item 5, declara as informações que devem obrigatoriamente constar da rotulagem de alimentos embalados: "denominação de venda do alimento, lista de ingredientes, conteúdos líquidos, identificação da origem, nome ou razão social e endereço do importador, no caso de alimentos importados, identificação do lote, prazo de validade e instruções sobre o preparo e uso do alimento, quando necessário". 0 item 6 , indica como devem ser apresentadas as informações obrigatórias. De acordo com o subitem 6.2.2., "todos os ingredientes devem constar na lista de ingredientes, em ordem decrescente da respectiva proporção". No subitem 6.2.4, os aditivos alimentares devem ser declarados depois dos ingredientes, devendo constar sua função principal e nome completo ou número do Sistema Internacional de Numeração (INS), ou ambos e para aromas ou aromatizantes declara-se somente a função. O subitem 6.7.1. descreve que "Quando necessário, o rótulo deve conter as instruções sobre o modo apropriado de uso, incluídos a reconstituição, o descongelamento ou o tratamento que deve ser dado pelo consumidor para o uso correto do produto" 6,8

No caso dos sucos e bebidas à base de frutas, o Decreto $n^{\circ} 2.314$, de 1997, complementa as informações obrigatórias que devem constar no rótulo. O Decreto $n^{\circ} 2.314$, em sua seção IV, do Cap. II, do Título I, declara que, o rótulo das bebidas deve conter "a expressão Indústria Brasileira, por extenso ou abreviada" 6 .

De acordo com a Lei $n^{\circ}$ 10.674, de 2003, "todos os alimentos industrializados deverão conter em seu rótulo e bula, obrigatoriamente, as inscrições contém Glúten ou não contém Glúten, conforme o caso" 10 .

A RDC $n^{\circ} 360$, de 2003, informa sobre a rotulagem nutricional obrigatória, corroborando a Portaria n² 27 , de 1998, que trata da informação nutricional complementar. De acordo com o item 2 de seu Anexo único, rotulagem nutricional "é toda descrição destinada a informar ao consumidor sobre as propriedades nutricionais de um alimento". A rotulagem nutricional "compreende a) a declaração de valor energético e nutrientes; b) a declaração de propriedades nutricionais (informação nutricional complementar)". A declaração 
de nutrientes "é uma relação ou enumeração padronizada do conteúdo de nutrientes de um alimento", já a declaração de propriedades nutricionais (informação nutricional complementar) "é qualquer representação que afirme, sugira ou implique que um produto possui propriedades nutricionais particulares, especialmente, mas não somente, em relação ao seu valor energético e conteúdo de proteínas, gorduras, carboidratos e fibra alimentar, assim como ao seu conteúdo de vitaminas e minerais" 10,11

Segundo o item 3, da RDC n 360, é obrigatório declarar na rotulagem nutricional "a quantidade do valor energético e dos seguintes nutrientes: carboidratos, proteínas, gorduras totais, gorduras saturadas, gorduras trans, fibra alimentar e sódio". A declaração do teor das vitaminas e minerais que constam no Anexo A é opcional, sempre e quando estiverem presentes em quantidade igual ou maior a 5\% da Ingestão Diária Recomendada (IDR) por porção indicada no rótulo" ${ }^{10}$. No subitem 3.4.1.2., consta que "a informação nutricional deve aparecer agrupada em um mesmo lugar, estruturada em forma de tabela, com os valores e as unidades em colunas. Se o espaço não for suficiente, pode ser utilizada a forma linear" ${ }^{10}$. No subitem 3.4.2., estão as unidades que devem ser utilizadas na rotulagem nutricional: valor energético em quilocalorias (kcal) e quilojoules (kJ), proteínas, carboidratos, gorduras e fibra alimentar em gramas ( $\mathrm{g}$ ), sódio e colesterol em miligramas $(\mathrm{mg})$, vitaminas e minerais em miligramas ( $\mathrm{mg}$ ) ou microgramas (mg), conforme expresso na Tabela de IDR do Anexo A, e porção em gramas $(\mathrm{g})$, mililitros $(\mathrm{mL})$ e medidas caseiras de acordo com o Regulamento Técnico específico. O subitem 3.4.4.1. estabelece que, "a informação nutricional deve ser expressa por porção, incluindo a medida caseira correspondente, segundo o estabelecido no Regulamento Técnico específico e em percentual de Valor Diário (\%VD). Fica excluída a declaração de gordura trans em percentual de Valor Diário (\%VD)" 10 .

A RDC n³59, de 2003, em seu Anexo único, define porção e medida caseira, e traz uma tabela de porções e critérios para sua aplicação na rotulagem nutricional. Em seu subitem 2.1., porção é definida como: "a quantidade média do alimento que deveria ser consumida por pessoas sadias, maiores de 36 meses de idade em cada ocasião de consumo, com a finalidade de promover uma alimentação saudável"12.

De acordo com o item 4, para se estabelecer o tamanho da porção tomou-se como base uma alimentação diária de $2000 \mathrm{kcal}$ ou $8400 \mathrm{~kJ}$ e os alimentos foram classificados em níveis e grupos com base no valor energético médio de cada grupo, no número de porções recomendadas e no valor energético médio correspondente à porção". De acordo com a Tabela III, da Resolução RDC n 359 de $2003^{12}$ Frutas, sucos, néctares e refrescos de frutas (1 porção aproximadamente $70 \mathrm{kcal})$, para suco, néctar e bebidas de frutas, a porção a ser declarada na rotulagem nutricional é de $200 \mathrm{~mL}$ e a medida caseira a ser utilizada é de 1 copo.

\section{Avaliação crítica da legislação brasileira de suco de fruta}

A legislação brasileira de suco de fruta é bastante abrangente. São contemplados diferentes tipos, que neste trabalho serão denominados sucos, de forma a englobar todos os sucos de fruta dispostos nesta legislação, inclusive o néctar. Os sucos devem atender à legislação específica ${ }^{5-7,13,14}$ e apresentar os requisitos mínimos de qualidade estabelecidos nas respectivas normas. Os sucos também devem atender à legislação sobre rotulagem de alimentos embalados ${ }^{8-12}$. Contudo, existem lacunas nesta legislação que favorecem a interpretação equivocada do consumidor e/ou do produtor, e possibilitam a introdução de sucos não regulamentados no mercado. Isso é agravado pelas sucessivas alterações nas normas e pela falta de padronização da terminologia empregada, bem como pela ausência de definições essenciais, dificultando a consulta e o conhecimento da legislação. Neste item serão abordados os aspectos críticos da legislação refe- 
rentes aos sucos, com ênfase no suco de fruta pronto para beber.

A legislação brasileira não define suco pronto para beber, embora a expressão seja citada na legislação do suco tropical (Art. 40, parágrafo $8^{\circ}$ do Decreto $n^{\circ} 3.510$, de 2000). Essa expressão se refere ao suco que está pronto para o consumo. Segundo tal legislação o termo pronto para beber pode ser declarado no rótulo "quando ao suco tropical for adicionado açúcar" (Art. 40, parágrafo $8^{\circ}$ do Decreto $n^{\circ}$ 3.510). Outros tipos de suco prontos para o consumo não apresentam o termo pronto para beber em sua legislação específica, como por exemplo, o suco e o néctar, embora se observe o emprego deste termo nos rótulos dos respectivos produtos disponíveis no mercado. Por outro lado, a definição de néctar (Art. 43 do Decreto $n^{\circ} 2.314$, de 1997) menciona que a bebida é destinada ao consumo direto.

Outro aspecto importante é sobre a definição de suco integral. A definição de suco reconstituído (Art. 40 do Decreto $n^{\circ} 2.314$ ) está baseada na definição de suco integral, que não é contemplada na legislação brasileira. É importante ressaltar que, segundo tal legislação, o suco reconstituído deve atender às especificações estabelecidas de acordo com o PIQ do suco integral de cada fruta, que não é encontrado na legis- lação vigente, com exceção do suco de caju (Instrução Normativa $n^{\circ} 1$, de 2000). Consequentemente, a legislação não estabelece os parâ-metros a serem seguidos para o suco reconstituído e abre uma brecha para a produção de sucos não regulamentados e que não dispõem de PIQ, como pode ser verificado de acordo com a Figura 1. O mesmo ocorre com suco desidratado. Além disso, o suco reconstituído, definido como o suco obtido pela diluição do "suco concentrado ou desidratado até a concentração original do suco integral" (ou ao teor de sólidos solúveis mínimo) estabelecida nos respectivos PIQ de suco integral de cada fruta (Art. 40 do Decreto $n^{\circ} 2.314$, de 1997), claramente confirma essa brecha. Paralelamente pode-se perceber que o termo suco integral está embutido na definição de suco, conforme consta no Art. 40 do Decreto $n^{\circ} 2.314$, que também permite uma brecha. A legislação (Instrução Normativa ${ }^{\circ}$ 1, de 2000) também não estabelece o regulamento técnico geral para fixação do PIQ para suco de fruta, embora estabeleça o PIQ do suco de cada fruta.

A adição de açúcar é permitida desde que seja declarada no rótulo do suco de fruta a expressão adoçado, como ocorre no caso do suco (Art. 22, Seção IV - Da rotulagem de bebidas, do Capítulo II, do Título I do Decreto n 2.314 , de 1997) e do suco tropical (Art. 40, parágrafo $8^{\circ}$,

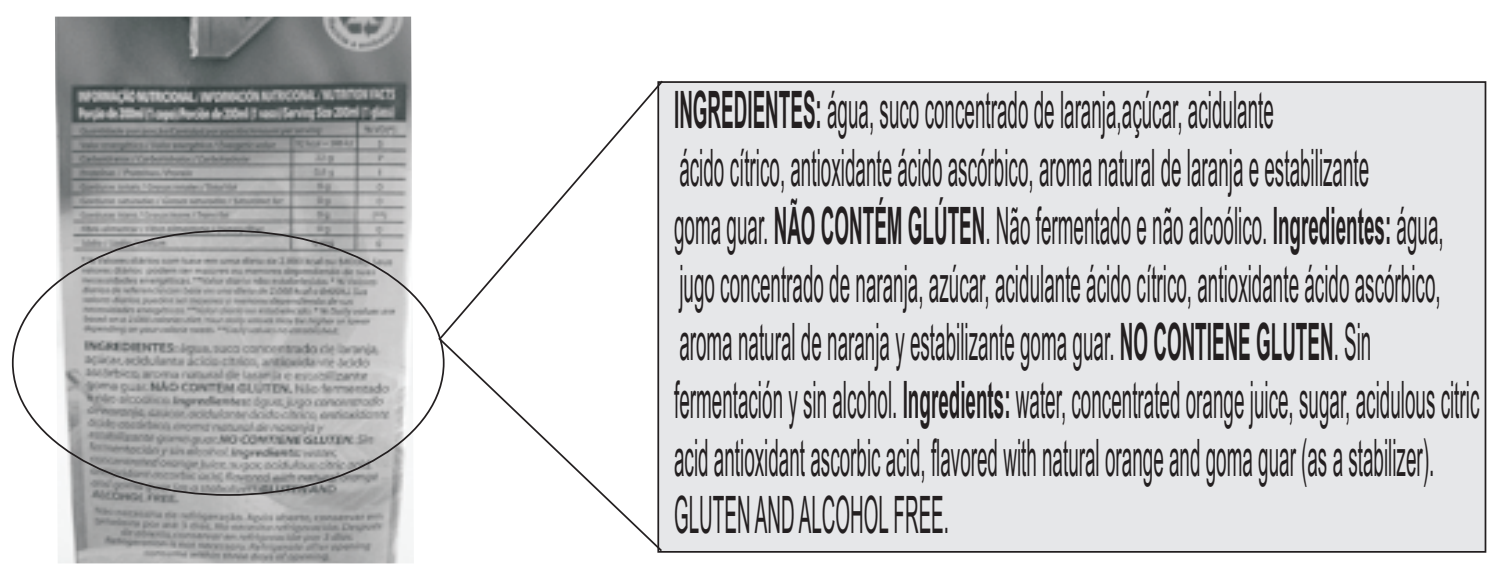

Figura 1. Lista de ingredientes típica de sucos de laranja prontos para beber obtidos a partir de suco concentrado. 
do Decreto $n^{\circ} 3.510$, de 2000). Contudo, tal exigência não se faz necessária no caso do néctar que, por definição sempre é adoçado. A expressão adoçado, presente no rótulo do suco e do suco tropical e ausente no rótulo do néctar, naturalmente, leva o consumidor a elevar a qualidade do néctar, favorecendo a interpretação equivocada. Segundo dicionários ${ }^{15,16}$ da língua portuguesa, na mitologia grega, néctar é a bebida dos deuses, à base de mel, deliciosa, saborosa, com propriedade de avivar os sentidos, conservar a eterna juventude e propiciar a imortalidade àqueles que a bebiam. O termo néctar, como utilizado pela legislação, não tem o mesmo significado daquele contido nos dicionários da língua portuguesa, o que também poderia justificar a interpretação equivocada do consumidor. Segundo Turra et al. ${ }^{17}$, o desconhecimento do consumidor sobre a composição do néctar e as informações do rótulo foram considerados como vantagem para o produtor, capaz de gerar assimetria informacional entre a percepção do consumidor e os diferentes tipos de suco disponíveis no mercado.

A legislação do suco tropical apresenta as frutas polposas de origem tropical (Art. $2^{\circ}$, da Instrução Normativa n 12 , de 2003) usadas na elaboração do suco tropical, embora não estabeleça o PIQ para todas essas frutas (Art. $1^{\circ}$, da Instrução Normativa $n^{\circ} 12$, de 2003). Também não há definição de fruta polposa de origem tropical, nem justificativa para a ausência do PIQ de algumas frutas polposas. Assim, qualquer fruta polposa de origem tropical mencionada em tal legislação poderá ser utilizada para a fabricação do suco tropical, configurando mais uma brecha. Paralelamente, a legislação estabelece para suco tropical (Instrução Normativa no 12 ), que a quantidade de polpa da fruta que não tenha o PIQ fixado deve ser no mínimo 50\% (m/m), com exceção das frutas com acidez alta ou conteúdo de polpa muito elevado ou sabor muito forte, cuja quantidade de polpa deve ser no mínimo 35\% $(\mathrm{m} / \mathrm{m})$.

Porém, não foram estabelecidos os valores (e/ou intervalos) a serem considerados e a interpre- tação fica a critério do produtor e/ou consumidor. O mesmo acontece com o néctar (Art. $3^{\circ}$ da Instrução Normativa $n^{\circ} 12$ ), para o qual a legislação estabelece que a quantidade de polpa da fruta que não tenha o PIQ fixado, deve ser no mínimo 30\% $(\mathrm{m} / \mathrm{m})$, com exceção das frutas com acidez alta ou conteúdo de polpa muito elevado ou sabor muito forte, cuja quantidade de polpa não deve ser menor que $20 \%(\mathrm{~m} / \mathrm{m})$. Em ambos os casos não estão estabelecidos os requisitos mínimos de qualidade que esses sucos tropicais e néctares devem apresentar. A ausência do PIQ de sucos tropicais e néctares de algumas frutas abre a brecha para sucos não regulamentados. O néctar de laranja é um exemplo típico. É uma bebida correntemente comercializada nos diferentes pontos de venda do país e que não tem PIQ estabelecido.

Um outro aspecto é sobre a definição do suco tropical encontrada no regulamento técnico para fixação do PIQ geral para suco tropical (Anexo I da Instrução Normativa $n^{\circ} 12$ ). A legislação define suco tropical como "o produto obtido pela dissolução, em água potável.....". Entretanto, no PIQ do suco tropical de cada fruta, a mesma legislação define suco tropical da fruta em questão como "a bebida obtida pela dissolução, em água potável....", evidenciando o emprego de terminologia diferente na legislação do mesmo produto.

A rotulagem dos sucos de fruta prontos para beber deve atender à legislação brasileira sobre rotulagem de alimentos embalados e estar de acordo com as exigências da legislação dos sucos de fruta. A rotulagem tem como objetivo informar a composição do alimento, suas características nutricionais, e alertar consumidores cuja restrição alimentar requeira informação sobre ingredientes específicos. As mudanças frequentes na legislação de rotulagem também podem levar à interpretação equivocada do consumidor e/ou produtor. Mudanças frequentes, e informações divergentes, em legislações de rotulagem concomitantemente vigentes, favorecem a falta de dis- 
cernimento em relação às diferenças existentes. Um exemplo deste fato é que estão em vigor, atualmente, três normas sobre a informação da presença de glúten no rótulo dos alimentos: a obrigatoriedade da declaração da presença de glúten nos alimentos que o contém ${ }^{18}$; a obrigatoriedade da declaração em todos os alimentos da expressão contém glúten ou não contém glúten conforme o caso, como ocorre com o suco de fruta, que tem em seu rótulo a expressão não contém glúten ${ }^{9}$; e como tal expressão deve ser declarada ${ }^{19}$. É possível optar pela norma mais conveniente.

Algumas marcas de suco de laranja pronto para beber não declaram no rótulo o uso de aromas/aromatizantes, embora a maioria declare corretamente seu emprego. Um outro aspecto interessante é que em algumas marcas de suco de laranja pronto para beber, a informação nutricional não está correta, não constando a declaração do valor energético em quilo joules (kj), nem dos teores de gorduras saturadas e trans, como exigido pela legislação atual ${ }^{10}$. Outras marcas não declaram na informação nutricional a medida caseira de um copo, exigida pela legislação ${ }^{12}$. Há também marcas que declaram incorretamente valores de ferro e cálcio na rotulagem nutricional, pois não atingiram a recomendação mínima de $5 \%$ da Ingestão Diária Recomendada (IDR) por porção, conforme exigido para que conste no rótulo ${ }^{10}$. Ainda, muitas marcas de suco de laranja pronto para beber declaram no rótulo que o produto é pronto para beber (Figura 1), embora a legislação não defina o termo pronto para beber, enquanto a maioria declara que não contém conservantes/conservadores, mesmo tendo declarado na lista de ingredientes o uso de aditivos permitidos em sucos, como antioxidantes, acidulantes, espessantes, regulador de acidez, antiespumante, conservador, emulsificante, estabilizante, realçador de sabor, espumante, umectante e sequestrante.

Por outro lado, também se pode considerar que é possível elaborar um rótulo de ali- mento com base na legislação de rotulagem. Apesar das diversas normas e das informações confusas em algumas delas, pode-se identificar as informações obrigatórias, as informações opcionais e complementares, as porções a serem declaradas, etc, que devem constar no rótulo de um alimento embalado.

Nesse sentido, a legislação brasileira de rotulagem deveria ser amplamente divulgada, visando facilitar o acesso e o entendimento do rótulo dos produtos, bem como contribuir para uma escolha consciente na hora da compra. Contudo, para que se possa conhecer e usar adequadamente a legislação é necessário torná-la clara e mantê-la constantemente atualizada. Caberia também aos órgãos responsáveis pela legislação, oferecer serviços de orientação e programas de educação voltados às necessidades da população e às exigências dos alimentos.

Finalmente, vale considerar que a legislação brasileira não estabelece os métodos de análise para avaliar os requisitos de qualidade dos sucos, limitando-se tão somente a citar alguns métodos de análise nas referências.

\section{CONSIDERAÇÕES FINAIS}

A legislação brasileira de sucos e bebidas à base de fruta é bastante ampla, abrangendo diferentes tipos, que devem atender à legislação específica para cada tipo e à legislação de rotulagem. Contudo, várias brechas foram identificadas na legislação de sucos. Não são definidos os termos suco pronto para beber e suco integral. O PIQ do suco integral de cada fruta não está estabelecido e é utilizado na definição de suco reconstituído e suco desidratado. A declaração adoçado, desnecessária no rótulo do néctar, leva o consumidor a compará-lo com o suco e o suco tropical, cuja declaração é obrigatória. O PIQ do suco tropical não está estabelecido para muitas das frutas polposas de origem tropical mencionadas na legislação. Para suco tropical e néctar, também não estão estabelecidos valores de acidez, de conteúdo de polpa e de intensidade de sabor 
forte para frutas que não tenham o PIQ estabelecido. Essas brechas favorecem a produção de sucos não regulamentados, como é o caso do néctar de laranja. A falta de padronização da terminologia e mudanças frequentes na legislação de rotulagem, também levam à interpretação equivocada da legislação.

A implementação de programas e medidas que visem a orientação e a educação dos consumidores para o uso adequado da rotulagem poderá contribuir para a escolha mais consciente do consumidor e para o aumento do consumo de suco de fruta.

\section{A GRADECIMENTO}

A Coordenação de Aperfeiçoamento de Pessoal de Nível Superior pela bolsa concedida.

\section{COLABORADORES}

M. MONTEIRO e K.O. SANTOS participaram da concepção do trabalho, da definição da metodologia e das informações necessárias, da definição sobre os alimentos objeto do estudo e os aspectos da legislação analisada, e ainda da correção e redação final do artigo. A.C. FERRAREZI foi responsável pela execução do trabalho, tendo interpretado e avaliado toda a legislação brasileira, além de ter redigido o trabalho. Ao debateram ao longo da realização de todo o trabalho os autores reuniram a percepção de cada na elaboração da avaliação crítica.

\section{REFERÊ NCIAS}

1. Datamark Market Intelligence Brazil. [cited Aug 11 2007]. Available from: <www.datamark.com.br>.

2. De Marchi R. Desenvolvimento de uma bebida a base de maracujá (Passiflora edulis Sims. F. flavicarpa Deg.) com propriedades de reposição hidrolítica [dissertação]. Araraquara: Universidade Estadual Paulista; 2001.

3. Pavan TA, Neves MF, Carvalho DT. O Processo de compra de suco de laranja por varejistas [Internet]. [acesso 2006 ago 11]. Disponível em: <http://www. abecitrus.com.br>.
4. Rosa SES, Cosenza JP, Leão LTS. Panorama do setor de bebidas no Brasil. BNDES Setorial. 2006; 23: 101-50.

5. Brasil. Ministério da Agricultura, Pecuária e Abastecimento. [Internet] Lei $n^{\circ} 8.918$, de 14 de Julho de 1994. Dispõe sobre a padronização, a classificação, o registro, a inspeção, a produção e a fiscalização de bebidas, autoriza a criação da comissão intersetorial de bebidas e dá outras providências. [acesso 2007 maio 17]. Disponível em: <http:// extranet.agricultura.gov.br/sislegisconsulta/ consultarLegislacao.do?operacao=visualizar\&id= 212>.

6. Brasil. Ministério da Agricultura, Pecuária e Abastecimento. Decreto $n^{\circ} 2.314$, de 04 de setembro de 1997. Regulamenta a Lei $n^{\circ} 8.918$, de 14 de julho de 1994, que dispõe sobre a padronização, a classificação, o registro, a inspeção, a produção e a fiscalização de bebidas. [acesso 2007 maio 17]. Disponível em: <http://extranet.agricultura.gov.br/ sislegisconsulta/consultarLegislacao.do?operacao= visualizar\&id=1010>.

7. Brasil. Ministério da Agricultura, Pecuária e Abastecimento [Internet]. Decreto $\mathrm{n}^{\circ} 3.510$, de 16 de junho de 2000. Altera dispositivos do Regulamento aprovado pelo Decreto $n^{\circ} 2.314$, de 4 de setembro de 1997, que dispõe sobre a padronização, a classificação, o registro, a inspeção, a produção e a fiscalização de bebidas. [acesso 2007 maio 17]. Disponível em: <http://extranet.agricultura.gov.br/sis legis-consulta/consultarLegislacao.do?operacao= visualizar\&id=1012>.

8. Brasil. Resolução RDC $n^{\circ} 259$, de 20 de setembro de 2002. A Diretoria Colegiada da ANVISA/MS aprova o regulamento técnico para rotulagem de alimentos embalados. Diário Oficial da União. 2002; 23 set; (184):33; Seção 1.

9. Brasil. Lei $n^{\circ} 10.674$, de 16 de maio de 2003. O Congresso Nacional obriga a que os produtos alimentícios comercializados informem sobre a presença de glúten, como medida preventiva e de controle da doença celíaca. Diário Oficial da União. 2003; 19 maio; (94):1; Seção 1.

10. Brasil. Resolução RDC n 360, de 23 de dezembro de 2003. A Diretoria Colegiada da ANVISA/MS aprova o regulamento técnico sobre rotulagem nutricional de alimentos embalados. Diário Oficial da União. 2003; 26 dez; (251):33; Seção 1.

11. Brasil. Portaria $n^{\circ} 27$, de 13 de janeiro de 1998. A secretaria de Vigilância Sanitária do MS aprova o regulamento técnico referente à informação nutricional complementar. Diário Oficial da União. 1998; 16 jan; (11-E):1; Seção 1.

12. Brasil. Resolução RDC n 359, de 23 de dezembro de 2003. A Diretoria Colegiada da ANVISA/MS 
aprova o regulamento técnico de porções de alimentos embalados para fins de rotulagem nutricional. Diário Oficial da União. 2003; 26 dez; (251): 28; Seção 1.

13. Brasil. Ministério da Agricultura, Pecuária e Abastecimento [Internet]. Instrução normativa $n^{\circ} 01$, de 7 de janeiro de 2000. Regulamento técnico geral para fixação dos padrões de identidade e qualidade para suco de fruta. [acesso 2007 maio 17]. Disponível em: <http://extranet.agricultura.gov.br/sis legisconsulta/consultarLegislacaodo?operacao= visualizar\&id=7777>.

14. Brasil. Ministério da Agricultura, Pecuária e Abastecimento [Internet]. Instrução normativa $n^{\circ} 12$, de 4 de setembro de 2003. Regulamento técnico geral para fixação de identificação e qualidade gerais para suco tropical. [acesso 2007 maio 17]. Disponível em: <http://extranet.agricultura.gov.br/sis legisconsulta/consultaLegislacao.do?operacao= visualizar\&id=2831>.

15. Grande dicionário Larousse cultural da língua portuguesa. São Paulo: Nova Cultural; 1999.

16. Ferreira $A B H$. Novo dicionário Aurélio da língua portuguesa. Rio de Janeiro: Nova Fronteira, 1998.
17. Turra C, Fernandes EAN, Tagliaferro FS, Bacchi MA. Assimetria informacional no mercado brasileiro de sucos de laranja. Anais do Congresso Brasileiro de Fruticultura; 2006; Cabo Frio. Cabo Frio: Sociedade Brasileira de Fruticultura; 2006.

18. Brasil. Agência Nacional de Vigilância Sanitária [Internet]. Lei $n^{\circ}$ 8.543, de 23 de dezembro de 1992. Determina a impressão de advertência em rótulos e embalagens de alimentos industrializados que contenham glúten, a fim de evitar a doença celíaca ou síndrome celíaca. [acesso 2007 maio 20]. Disponível em: <http://e-legis.anvisa.gov.br/leisref/ public/showAct.php?id=32>.

19. Brasil. Resolução RDC $n^{\circ} 40$, de 08 de fevereiro de 2002. A Diretoria Colegiada da ANVISA/MS aprova o regulamento técnico para rotulagem de alimentos e bebidas embalados que contenham glúten. Diário Oficial da União. 2002; 13 fev; (29): 34; Seção 1.

Recebido em: 15/10/2008

Versão final reapresentada em: 24/2/2010 Aprovado em: 18/3/2010 